\title{
Techno-Economic Evaluation of Renewable Energy Projects using the Software GREENIUS
}

\author{
Jürgen Dersch *, Simon Dieckmann \\ Institute of Solar Research, German Aerospace Center DLR, 51170 Köln, Germany
}

\begin{abstract}
The software greenius which is made for fast and easy annual performance simulations of different renewable energy systems is introduced and two illustrative examples are shown. These examples are a $50 \mathrm{MW}$ CSP plant and a $50 \mathrm{MW}$ PV plant at the same site in Jordan. Different annual and diurnal output profiles as well as the different total electricity production despite identical nominal output are shown and discussed.
\end{abstract}

Keywords: Solar electricity, modelling, annual performance simulation, software

\section{Introduction}

A specific feature of most renewable energy sources like solar and wind is their fluctuating availability. Thus the expected total annual production and economic evaluation of power plants generating electricity from solar or wind cannot be estimated just from the calculation of a few steady state operating points. Instead an annual performance simulation with at least hourly time steps using a typical meteorological year is state-of-the-art. Local conditions like available solar irradiance or wind velocity are the main impact parameters and their instantaneous values determine the plant output.

The software tool greenius is being developed since several years at DLR and since December 2013 a free version with full functionality is available from [1]. It is continuously maintained and developed which includes the addition of new features and bug fixing. greenius may be used for feasibility studies as well as for technology comparisons, for educational purposes as well as for due diligence studies. Of course greenius is an engineering tool, not a "one-click-tool". Users must be careful about the input data as well as capable of evaluating and verifying the output by plausibility checks. However, the given default values and example projects make the access to the software easy.

This paper gives a short overview about the software and an application example for a site in Jordan.

\section{The software Tool greenius}

The main focus of greenius is on concentrating solar power plants and for this technology the most detailed models are implemented. Furthermore the following technologies may be simulated by greenius: process heat generation by concentrating and non-concentrating solar collectors, solar cooling, PV systems and wind power parks.

greenius comes with some example projects and users may adapt them to their own needs or create simulation projects from scratch. All input datasets may be edited in order to adapt them to specific conditions prevailing at the individual site. Meteorological data is an input to greenius and users must provide this dataset in a specific format. Import filters ease the use of several data format typical sources for meteorological data. The default temporal resolution used is one hour but even smaller time steps are possible, down to 10 minutes, provided that the meteorological data is available in this resolution. Further reduction of time steps is not considered reasonable since it is based on steady state models and cannot be used to study dynamic effects.

greenius offers also an economical calculation of the renewable power plants considering investment costs, O\&M costs as well as financing costs over a user defined period. Economic output variables are amongst others: Levelized cost of electricity (LCOE), internal rate of return (IRR), net present value and

${ }^{*}$ Corresponding author. Tel.: +49 22036012219

Fax: +49 2203 6014141; E-mail: Juergen.Dersch@dlr.de

(C) 2015 International Association for Sharing Knowledge and Sustainability

DOI: $10.5383 /$ ijtee. 10.01 .003 
payback times. Further details can be found in [1] and [2]. It is obvious that the results of the economical calculation will heavily depend on the input for component costs and it should be mentioned that greenius does not contain an up to date cost database. This task is left to users.

\section{Example projects}

\subsection{Site and Technologies}

The site chosen for this illustrative example is close to Queen Alia International Airport in Jordan. This site was chosen because of the availability of meteorological data files with the required temporal resolution. These meteorological data files were generated with the software Meteonorm 7.1 [3]. They are based on satellite data and ground measurements taken at the airport. The annual solar resources for this site derived by Meteonorm are $2460 \mathrm{kWh} / \mathrm{m}^{2}$ for direct normal irradiance (DNI) and $2088 \mathrm{kWh} / \mathrm{m}^{2}$ for global horizontal irradiance (GHI). Thus the site would be considered as good site for solar power production.

The RE technologies considered in this example are a concentrating solar power (CSP) plant using parabolic trough collectors and a photovoltaic power plant.

The CSP plant has a nominal gross output of $50 \mathrm{MWe}$ and is equipped with a thermal storage (TES) with 7 hours of full load capacity. This allows for electricity production even during non-sunshine hours but requires also a larger solar field in order to produce heat in excess to the power block demand during daytime to charge the TES. The solar field is made of 624 Eurothrough collectors arranged in 156 loops of 4 collectors. Their tracking axis is oriented south north, thus they are tracking the sun from east to west during the day. The solar field layout and size is chosen similar to the layout of the Andasol 1 and Andasol 2 plants in southern Spain. The TES is of the 2-tank molten salt type which has been applied in several parabolic trough plants worldwide. The power block is equipped with an air cooled condenser in order to minimize water consumption.
The PV plant has also a nominal output of $50 \mathrm{MWe}$. It is made of 177000 Yingli Panda YL280C Modules connected to 75 SMA Sunny Central 800CP inverters. These modules and inverters are chosen since their technical data is delivered with greenius. Other configurations and other modules are also possible and would change the results in detail, but not generally. The PV modules are installed on fixed racks facing towards south with $30^{\circ}$ elevation.

It should be mentioned that both plants have not been optimized technically by performing a detailed study. E.g. the number of parabolic trough collectors and the storage size for the CSP plants were not varied to look for an optimal configuration concerning the levelized cost of electricity (LCOE). Furthermore different PV modules and inverter types were not investigated. This would need much more effort and is typically done within a detailed feasibility study. Thus the results may just be used as indicative and not as ultimate. This applies particularly for the cost data. Nevertheless the results give a rough overview about the range of electricity production rates and costs.

\subsection{Simulation}

For an annual performance simulation with greenius the plant must be designed and all input data must be provided. greenius comes with a couple of datasets for individual collectors, modules, inverters, etc. These datasets may be used to set up the whole plant.

Figures 1 and 2 show the datasets for the key components in both plants, the parabolic trough collector for CSP and the solar panel for PV.

Beside this input of component datasets the whole plant must be designed in the sense that user must define the connection of individual modules as well as the orientation. This is shown in figures 3 and 4. greenius allows for different orientations, thus users may investigate the impact of this parameter on annual performance.

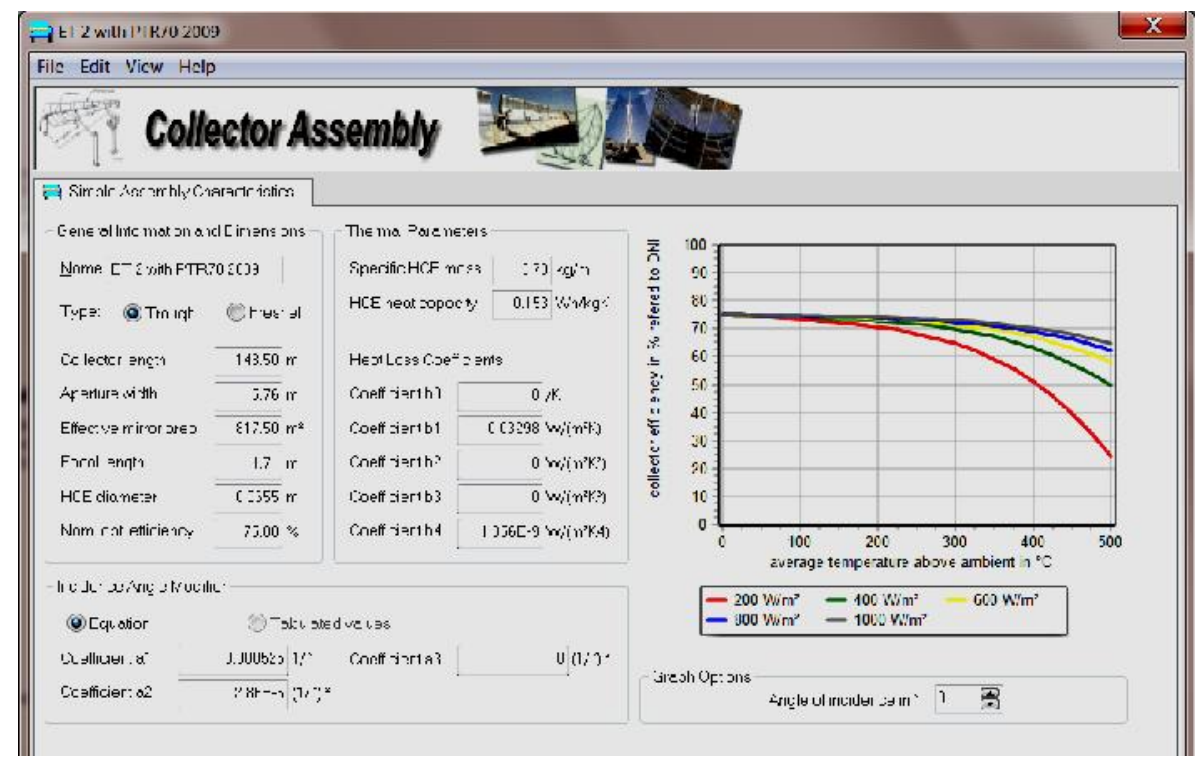

Fig. 1: Screenshot of the parabolic trough collector dataset used for the study 


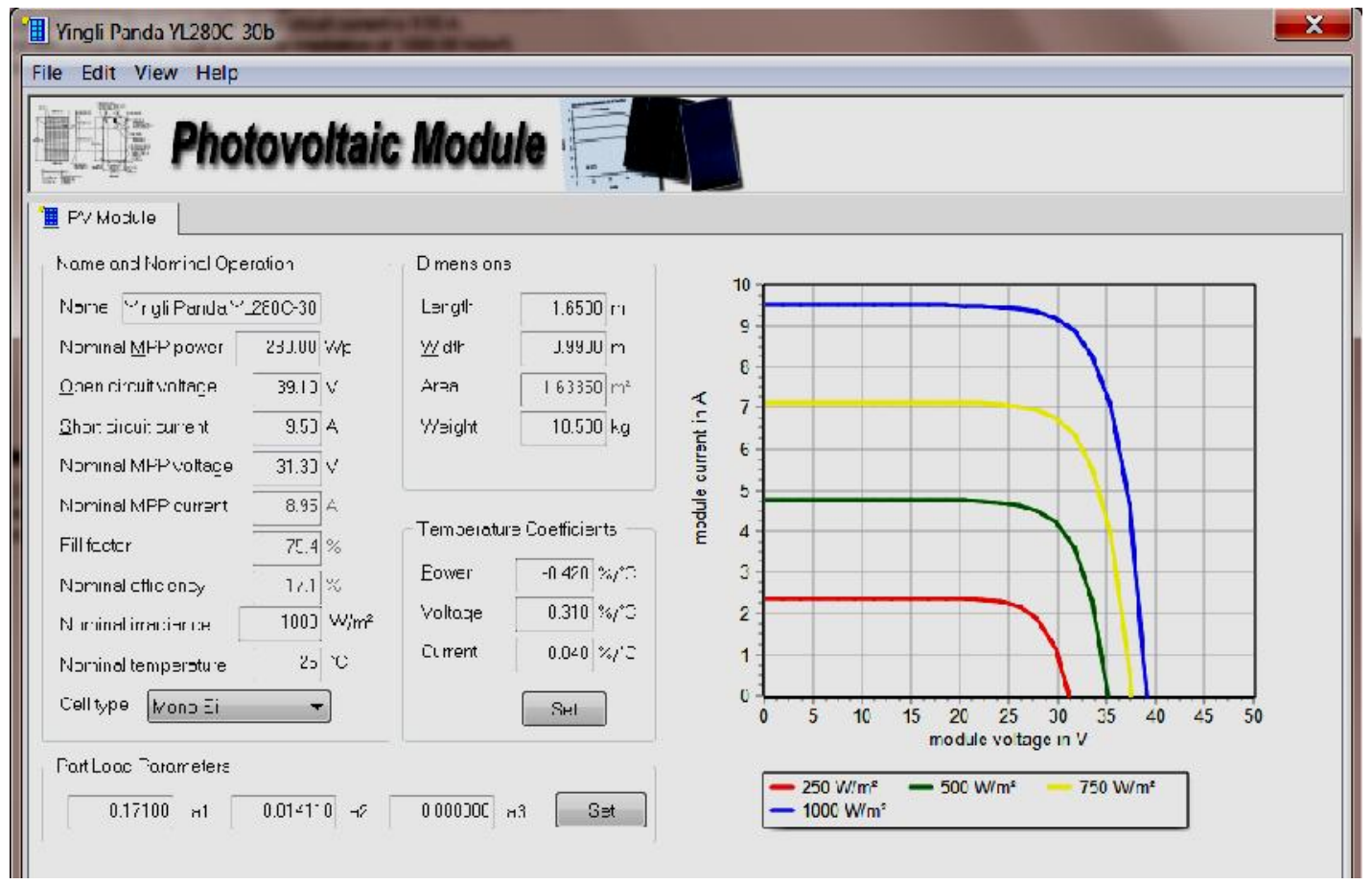

Fig. 2: Screenshot of the PV module dataset used for the study

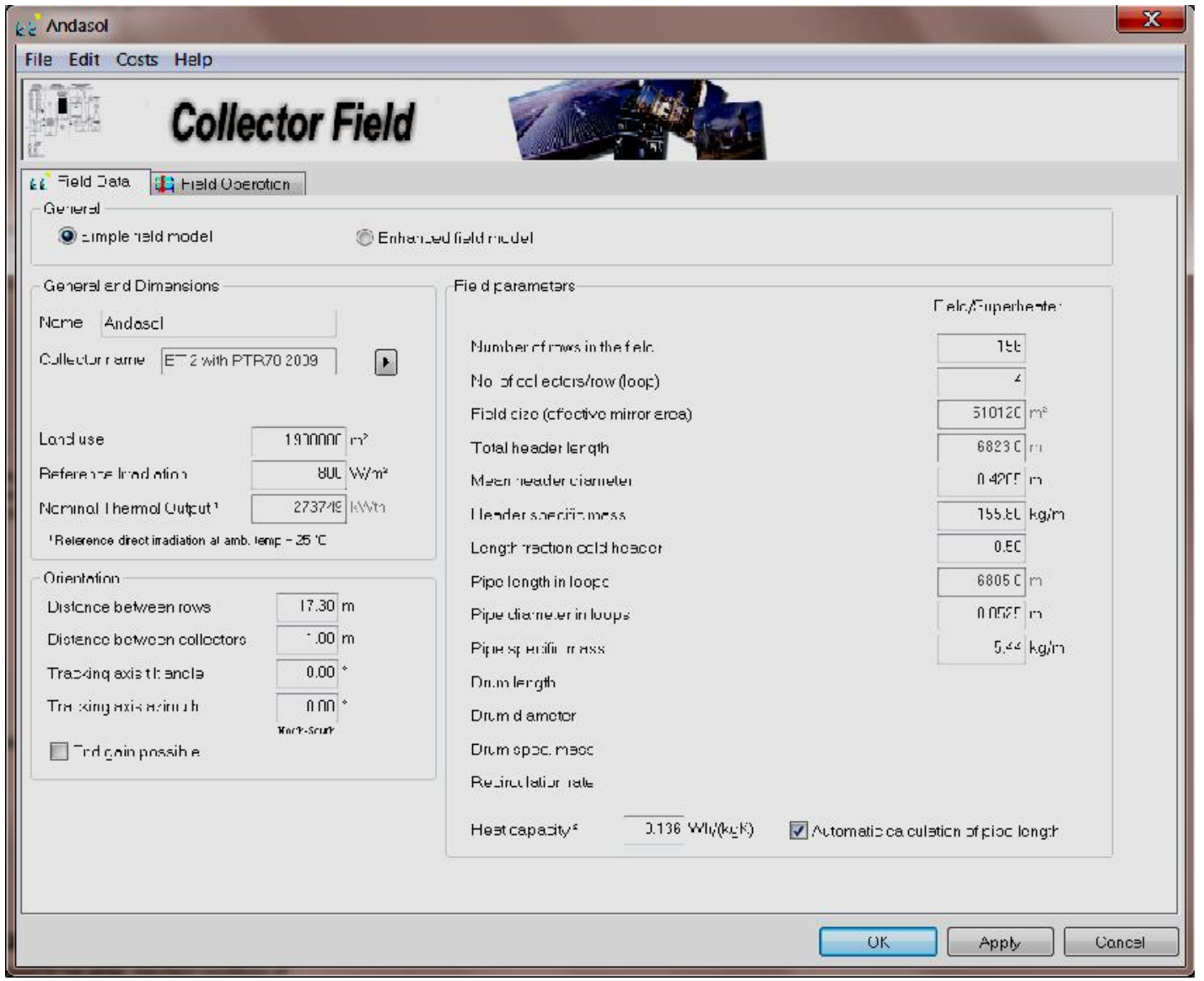

Fig. 3: Screenshot of the greenius input window for solar field layout 


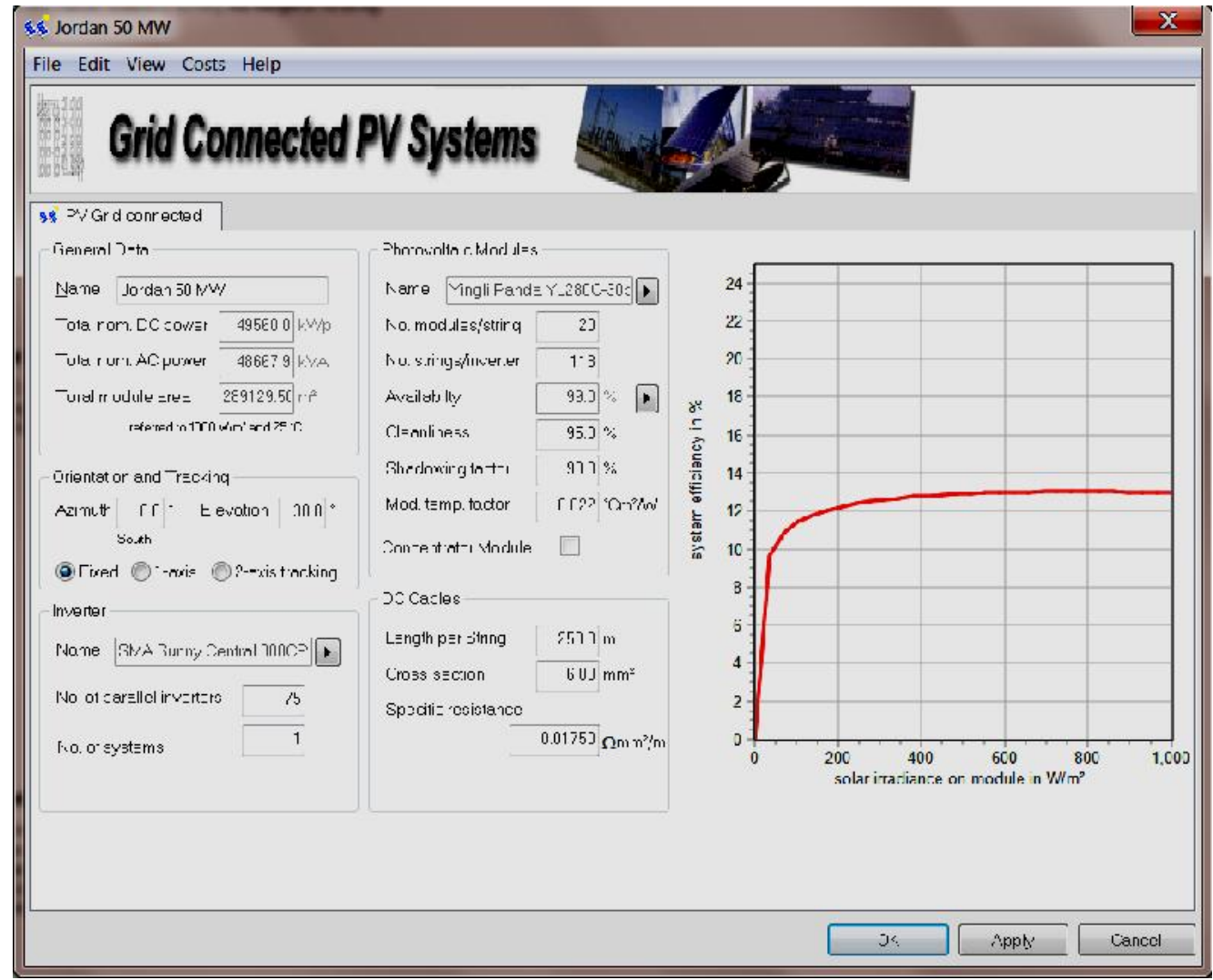

Fig. 4: Screenshot of the greenius input window for PV system layout

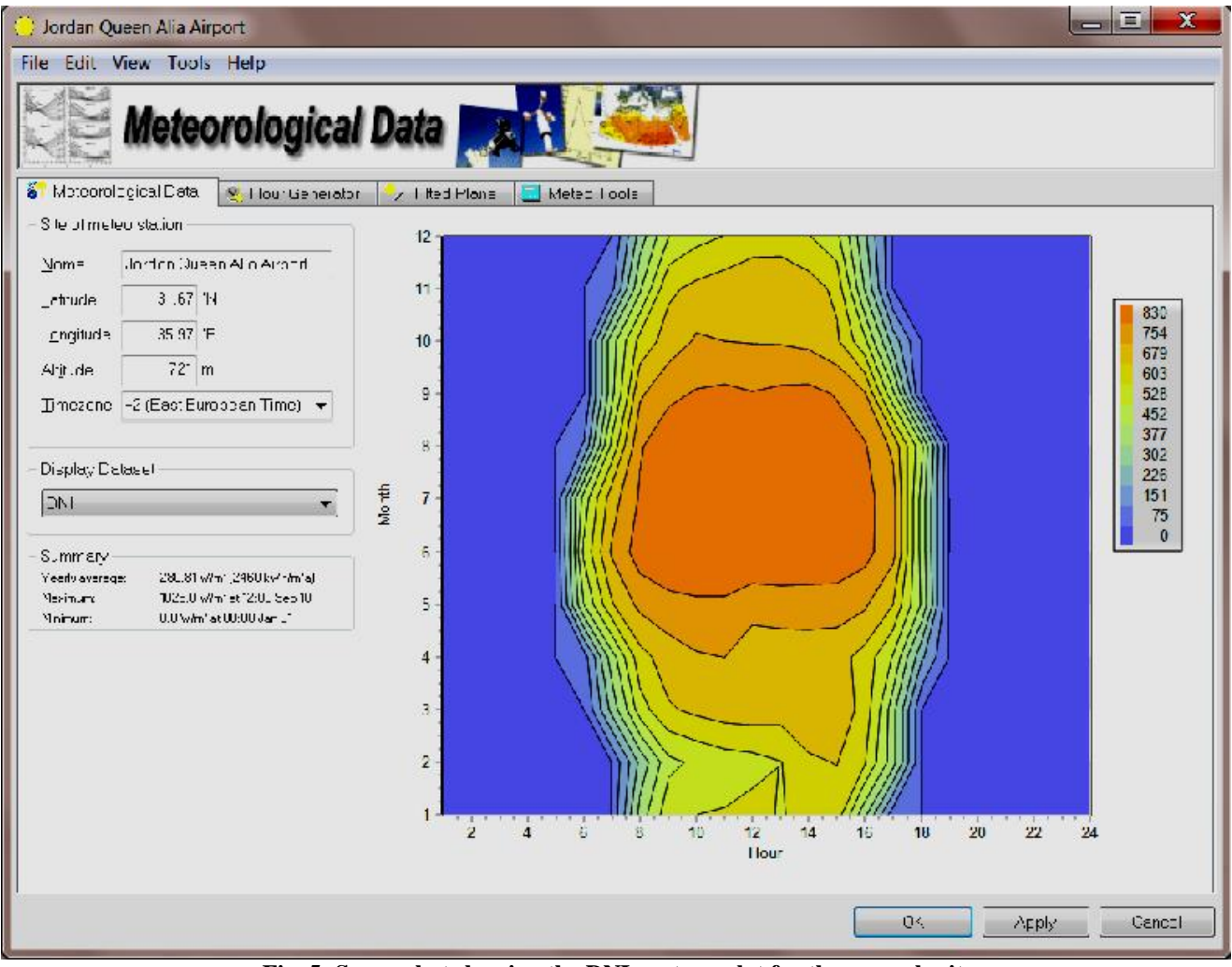

Fig. 5: Screenshot showing the DNI contour plot for the example site 
Figure 5 shows a screenshot representing the annual distribution of DNI for this example. On the abscissa the hours per day and on the ordinate the individual months are shown. This graph shows the effect of daylight hours and the higher intensity of solar irradiance in summer.

Once all required input is defined the simulation itself can be done very fast and needs only about 3-4 seconds on a modern personal computer. This time interval is valid for the simulation of the CSP plant with hourly meteorological data and according time steps. The PV plant simulation is even faster since the models are somewhat simpler. When changing to 10 minutes temporal resolution the simulation of a whole year needs about 12 seconds for the CSP plant which is caused by the additional number of time steps. Even this simulation may be considered as very fast and it allows for easy parameter variation in short time periods.

\subsection{Annual Results}

The major input data and results of the simulation for both plants with hourly resolution are given in table 1 .

Although the nominal power of both plants is identical, the aperture area and the land utilization are quite different. This is among other reasons due to the different definition of nominal power. For the PV plant, the nominal power is defined as peak power under laboratory conditions (irradiance $1000 \mathrm{~W} / \mathrm{m}^{2}$ and module temperature of $25^{\circ} \mathrm{C}$ ). For the CSP plant the nominal power is defined according to the nominal turbine rating for continuous operation. Furthermore the CSP plant has a TES which allows for many more full load hours throughout the year. Actually both plants do not deliver $50 \mathrm{MW}$ of electricity to the grid since the CSP plant has a considerable auxiliary consumption which reduces the net output. The PV plant has also some losses caused by cables and inverters but mainly suffers from increased module temperatures at high irradiance. As a result the CSP plant has 2846 hours with a net electricity output above $40 \mathrm{MW}$ while the PV plant has only 27 hours with a net electricity output above $40 \mathrm{MW}$.

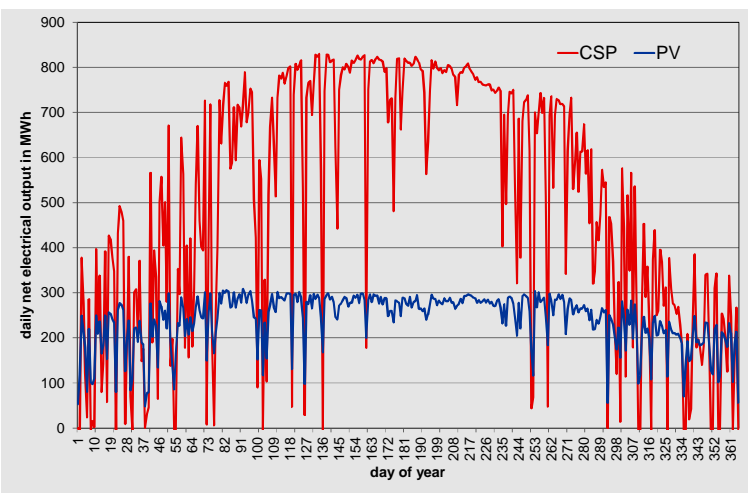

Fig. 6: Daily net electricity production of the CSP and the PV plant

Table 1: Major results of the annual calculation

\begin{tabular}{|l|c|c|l|c|} 
RE plant & CSP & PV & Unit & Ratio \\
\hline Nominal power & 50 & 50 & MW & 1.0 \\
\hline Total aperture area & 510,150 & 289,130 & $\mathrm{~m}^{2}$ & 1.8 \\
\hline Total land area & $1,785,525$ & 505,978 & $\mathrm{~m}^{2}$ & 3.5 \\
\hline Net electric output & 184.4 & 85.4 & GWh/year & 2.2 \\
\hline Total invest costs & 288 & 85 & Mio. $€$ & 3.4 \\
\hline Spec. invest costs & 5760 & 1700 & $€ / \mathrm{kW}$ & 3.4 \\
\hline LCOE & 156 & 100 & $€ / \mathrm{MWh}$ & 1.6 \\
\hline
\end{tabular}

The CSP plant needs about 3.5 times more land than the PV plant but it produces about 2.2 times more electricity.

Comparison of LCOE shows that the electricity generated by CSP is more expensive but on the other hand it is dispatchable electricity which offers a higher value for many grids [4], particularly with a higher share of electricity generated from solar. LCOE values shown are just for demonstration and the economical input parameters are not based on offers nor are they adapted to a specific project.

The seasonal distribution of electricity from both plants is shown in figures 6 . It is obvious that the CSP plant produces much more electricity during summer which is caused by longer sunshine periods, favourable sun angles and higher DNI compared to winter months. On the other hand there are several days for which the output of the CSP plant is zero but the PV plant delivers some output. These are typical days with high cloud coverage when the DNI is zero but the GHI is available.

\subsection{Results for Individual Days}

Figure 7 shows four days with good irradiation conditions in early spring, summer, autumn and winter. In addition to the DNI and GHI curves the hourly net electricity production for both plants is plotted. 

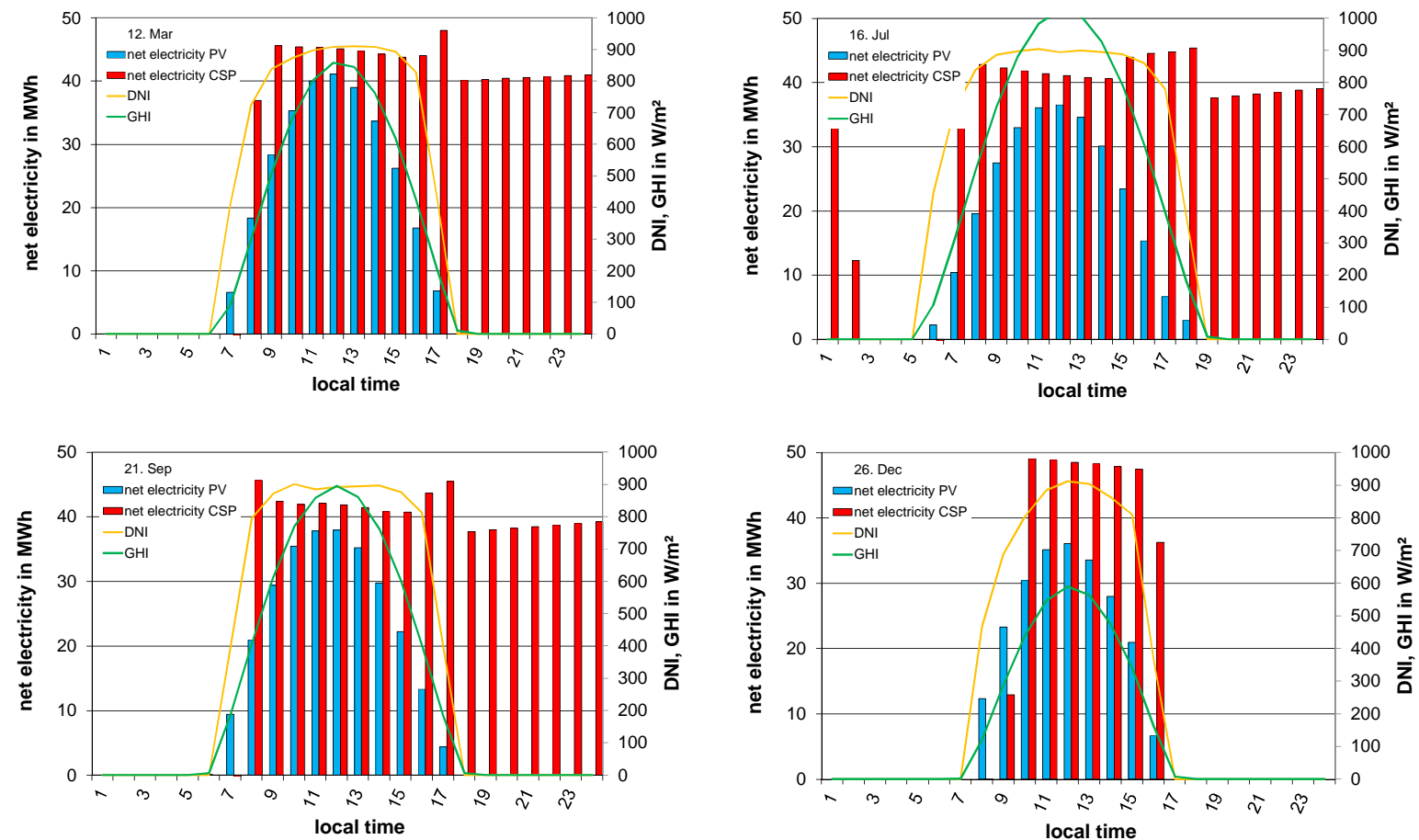

Fig. 7. Electricity production and irradiation for individual days throughout the year

In general the PV plant starts electricity production earlier than the CSP plant since the latter one must be heated up in the early morning hours after sunrise. It starts about one hour later than the PV plant. On the other hand, the CSP plant then continues production at almost constant power for several hours. During 3 of the days shown in figure 7 the electricity production of the CSP plant lasts until midnight due the fact that the TES could be charged to a high level during the day. Slightly decreasing electrical output after noon is caused by increasing ambient temperatures. The maximal output in the $16^{\text {th }}$ or $17^{\text {th }}$ hour is caused by the fact that the heat delivered by the solar field decreases because the TES is fully charged. This in turn leads to a reduced mass flow rate through the solar field and to lower pumping power which means higher net electricity output. The same reason leads to the high net electricity output for the CSP plant during daylight hours in December. Due to low sun angles the heat production of the solar field is not high enough to charge the storage. This means that the heat transfer fluid mass flow rate in the solar field is only at about $50 \%$ of its nominal value with accordingly low pumping power consumption and high net electricity output.

The distribution of net electricity production of the CSP plant over the day may be just considered as example. Due to the TES it could also be shifted towards evening hours or expanded to more hours with reduced hourly output.

For the CSP plant the "solar-only" operating strategy was assumed which means that the power block is operated whenever enough solar heat is available. Solar heat which cannot be used by the power block is used to charge the storage. The excess solar heat is dumped. When there is not enough solar heat to run the power block at full load, the heat to the power block is filled up with heat from the storage. After sunset the power block is operated at maximal possible load from TES until the storage is empty. This simple operating strategy ensures the utilization of the maximum amount of solar heat but does not always fit to local conditions. greenius offers also the option to do simulations with user-defined operating strategies to adapt the electricity production to local conditions.

\subsection{Impact of Time Resolution on the Results}

It is common sense among experts for solar power plants that simulation of typical years is required for a reliable yield analysis. Consideration of only a few operating points is not sufficient. Discussion about the required temporal resolution is not completed. Today simulation of hourly time steps may be considered as state-of-the-art for CSP plants because the DNI datasets are often available in this time resolution. Since more ground measurements in relevant regions become available which are typically stored as 10 minutes mean datasets, this time step is often discussed as the appropriate one.

greenius is fast enough to do the simulations in 10 minutes time steps and a numerical experiment was performed in order to identify the impact of the time resolution on the annual electricity output.

Figure 8 shows an example for the difference between $10 \mathrm{~min}$ and hourly data of DNI at the site. It is just an example and there are days with less and also days with more variation between both datasets. From this figure it becomes obvious that the temporal resolution of the simulation might have a considerable impact on plant output. In figure 9 the calculated thermal output from the solar field is shown for the same day. Large differences occur mainly for early morning and late afternoon hours. 


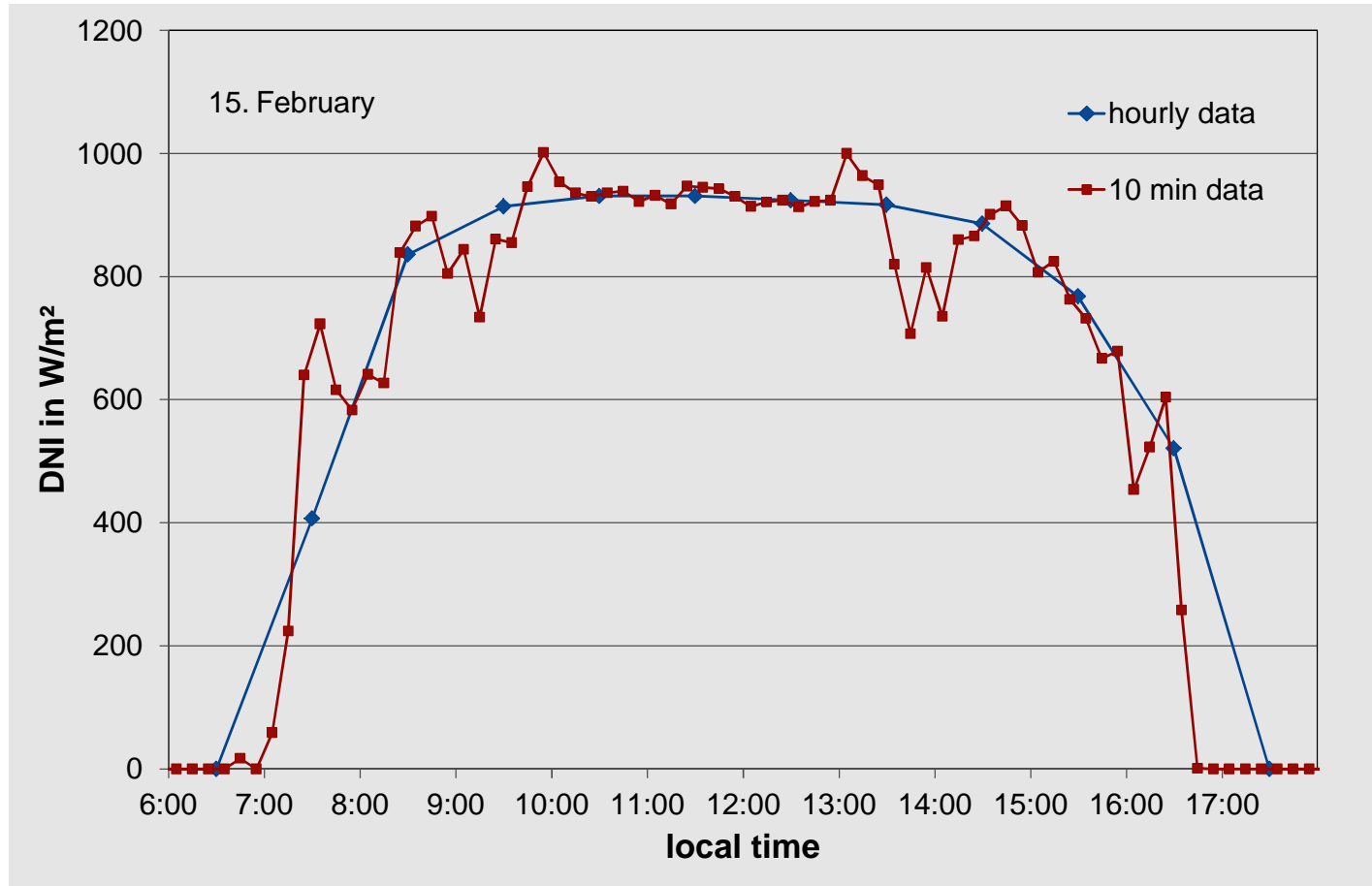

Fig. 8: DNI variation for one single day with hourly and 10 minutes temporal resolution

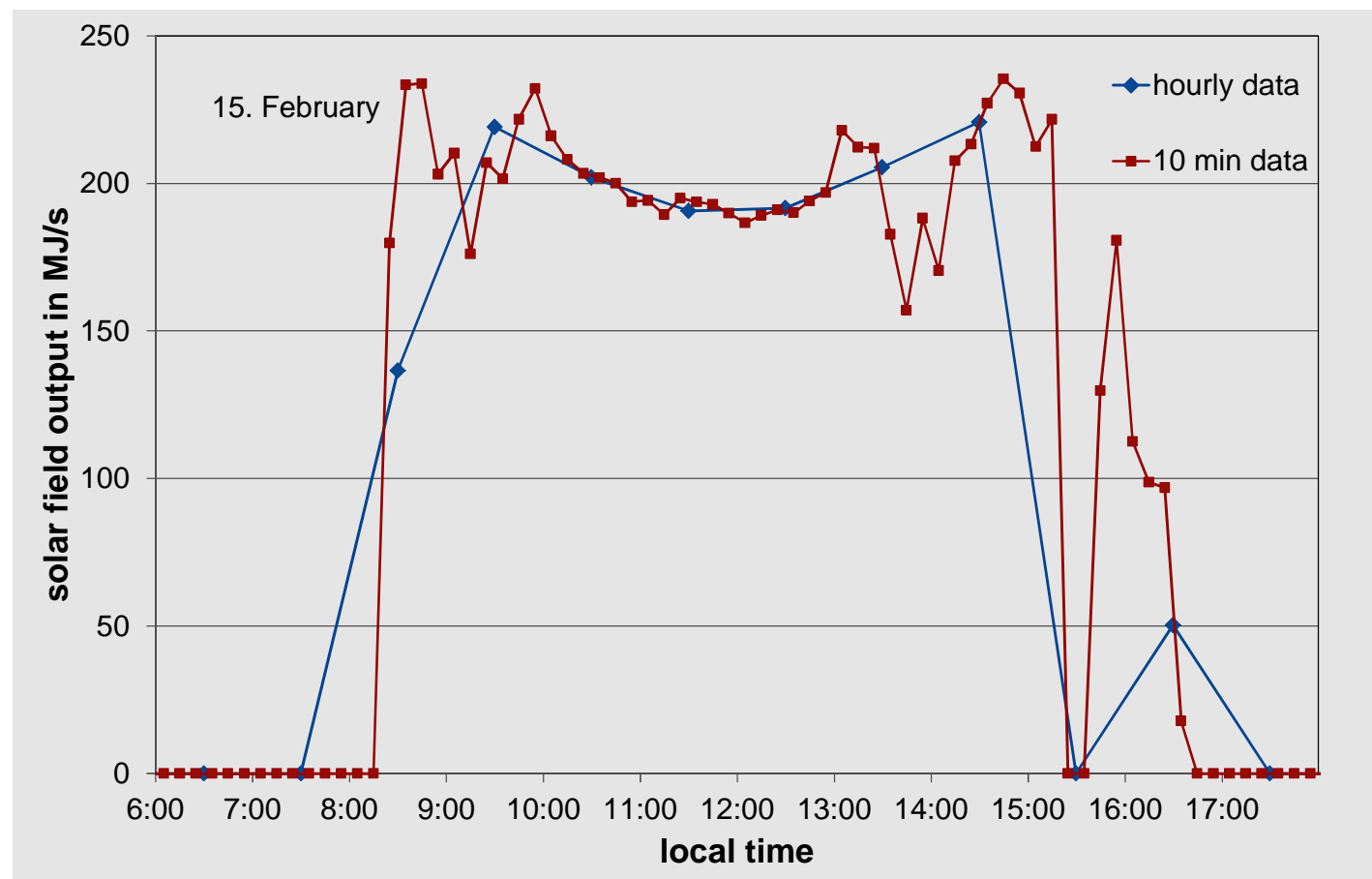

Fig. 9: Calculated thermal output of the solar field for one single day with hourly and 10 minutes temporal resolution

The most important figure for annual performance calculation is the annual net electricity output, which is typically used for economic evaluation of projects. Table 2 shows the calculated net electricity output for both plants for the different temporal resolutions. The net electricity production for the CSP plant shown in table 2 differs from the value shown in table 1 because by default greenius is using an internal time step adaption which subdivides the hourly time steps into much smaller intervals in order to account for effects which may occur between two timestamps. Such effects are e.g. transition from solar field heating up into production mode or reaching the maximal storage tank level. Therefore the greenius results for the CSP plant shown in table 1 are actually not strictly representing hourly simulation steps and the internal time step adaption was switched off to produce the results shown in table 2. 
Table 2: Impact of temporal resolution on the calculated annual electricity production

\begin{tabular}{|l|c|c|l|} 
RE plant & CSP & PV & Unit \\
\hline Nominal power & 50 & 50 & MW \\
\hline Net electric output $(60 \mathrm{~min})$ & 185.5 & 85.4 & GWh/year \\
\hline Net electric output $(10 \mathrm{~min})$ & 183.2 & 88.7 & GWh/year \\
\hline Difference & 1.3 & -3.7 & $\%$ \\
\hline
\end{tabular}

The error caused by hourly time steps for both plants shows opposing trends. The output of the CSP plant is overestimated by about $1.3 \%$ while the output of the PV plant is underestimated by $3.7 \%$ provided that the 10 min simulation represents the correct value. This result is not a general one but the values may be considered as estimation for the range of this error. The internal time step adaption of greenius reduces the difference by about one half and is particularly helpful when the meteorological data is only available with hourly resolution.

\section{Conclusions}

The software tool greenius is introduced and two illustrative examples are shown. The software may be used for feasibility studies as well as for educational purposes. The software is available free of charge from [2]. It will be further developed in order to allow for simulation of other plant configurations as well as with respect to more detailed models.

The differences in annual output between a PV plant and a CSP plant with thermal storage at the same site in Jordan are shown and discussed. Though the nominal power of both plants is identical the net electrical output may differ significantly. This is valid for instantaneous values and particularly for accumulated energy production for individuals days, months or years.

\section{Acknowledgments}

Publishing and further development of greenius is enabled trough funding by the German Federal Ministry for Economic Affairs and Energy on the basis of a decision by the German Bundestag (Funding reference number: 0325427).

\section{References}

[1] FreeGreenius Website: http://freegreenius.dlr.de

[2] Dersch J., Hennecke K., Quaschning V., Free Greenius New Options and Availability, SolarPACES 2012 Conference, 11.-14. September 2012, Marrakech, Morocco

[3] METEONORM Website: http://meteonorm.com/en/

[4] Jorgenson J, Denholm P, Mehos M, Estimating the Value of Utility-Scale Solar Technologies in California under a 40\% Renewable Portfolio Standard, Technical Report NREL/TP-6A20-61685, May 2014. 